\title{
Left Ventricular Aneurysm
}

National Cancer Institute

\section{Source}

National Cancer Institute. Left Ventricular Aneurysm. NCI Thesaurus. Code C102654.

A bulge or ballooning in the wall of the left ventricle of the heart. 